\title{
Male sex may not be associated with worse outcomes in primary all-posterior adult spinal deformity surgery: a multicenter analysis
}

\author{
David B. Bumpass, MD, ${ }^{1}$ Lawrence G. Lenke, MD, ${ }^{2}$ Jeffrey L. Gum, MD, ${ }^{3}$ \\ Christopher I. Shaffrey, MD, ${ }^{4}$ Justin S. Smith, MD, PhD, ${ }^{4}$ Christopher P. Ames, MD, ${ }^{5}$ \\ Shay Bess, MD, ${ }^{6}$ Brian J. Neuman, MD, ${ }^{7}$ Eric Klineberg, MD, ${ }^{8}$ Gregory M. Mundis Jr., MD, ${ }^{9}$ \\ Frank Schwab, MD, ${ }^{10}$ Virginie Lafage, PhD, ${ }^{10}$ Han Jo Kim, MD, ${ }^{10}$ Douglas C. Burton, MD, ${ }^{11}$ \\ Khaled M. Kebaish, MD, ${ }^{7}$ Richard Hostin, MD, ${ }^{12}$ Renaud Lafage, MS, ${ }^{10}$ and \\ Michael P. Kelly, MD, MSc, ${ }^{13}$ for the International Spine Study Group
}

1'Department of Orthopaedic Surgery, University of Arkansas for Medical Sciences, Little Rock, Arkansas; ${ }^{2}$ Department of Orthopaedic Surgery, Columbia University, New York, New York; ${ }^{3}$ Department of Orthopaedic Surgery, Norton Leatherman Spine Center, Louisville, Kentucky; ${ }^{4}$ Department of Neurological Surgery, University of Virginia, Charlottesville, Virginia; ${ }^{5}$ Department of Neurological Surgery, University of California, San Francisco, California; ${ }^{6}$ Denver International Spine Center, Presbyterian St. Luke's/Rocky Mountain Hospital for Children, Denver, Colorado; 'Department of Orthopedic Surgery, Johns Hopkins University, Baltimore, Maryland; ${ }^{8}$ Department of Orthopedic Surgery, University of California, Davis, Sacramento, California; ${ }^{9}$ San Diego Center for Spinal Disorders, San Diego, California; ${ }^{10}$ Division of Spine Surgery, Hospital for Special Surgery, New York, New York; ${ }^{11}$ Department of Orthopedic Surgery, University of Kansas, Kansas City, Kansas; ${ }^{12}$ Baylor Scoliosis Center, Plano, Texas; and ${ }^{13}$ Department of Orthopaedic Surgery, Washington University in St. Louis, Missouri

OBJECTIVE Adolescent spine deformity studies have shown that male patients require longer surgery and have greater estimated blood loss (EBL) and complications compared with female patients. No studies exist to support this relationship in adult spinal deformity (ASD). The purpose of this study was to investigate associations between sex and complications, deformity correction, and health-related quality of life (HRQOL) in patients with ASD. It was hypothesized that male ASD patients would have greater EBL, longer surgery, and more complications than female ASD patients.

METHODS A multicenter ASD cohort was retrospectively queried for patients who underwent primary posterior-only instrumented fusions with a minimum of 5 levels fused. The minimum follow-up was 2 years. Primary outcomes were EBL, operative time, intra-, peri-, and postoperative complications, radiographic correction, and HRQOL outcomes (Oswestry Disability Index, SF-36, and Scoliosis Research Society-22r Questionnaire). Poisson multivariate regression was used to control for age, comorbidities, and levels fused.

RESULTS Ninety male and 319 female patients met the inclusion criteria. Male patients had significantly greater mean EBL (2373 ml vs $1829 \mathrm{ml}, \mathrm{p}=0.01)$. The mean operative time, transfusion requirements, and final radiographic measurements did not differ between sexes. Similarly, changes in HRQOL showed no significant differences. Finally, there were no sex differences in the incidence of complications (total, major, or minor) at any time point after controlling for age, body mass index, comorbidities, and levels fused.

CONCLUSIONS Despite higher EBL, male ASD patients did not experience more complications or require less deformity correction at the 2-year follow-up. HRQOL scores similarly showed no sex differences. These findings differ from adolescent deformity studies, and surgeons can counsel patients that sex is unlikely to influence the outcomes and complication rates of primary all-posterior ASD surgery.

https://thejns.org/doi/abs/10.3171/2017.9.FOCUS17475

KEY WORDS adult spinal deformity; gender; sex; complications; deformity correction; blood loss; patient-reported outcomes; health-related quality of life

ABBREVIATIONS AIS = adolescent idiopathic scoliosis; $\mathrm{ASD}=$ adult spinal deformity; $\mathrm{BMI}=$ body mass index; $\mathrm{CCl}=\mathrm{Charlson}$ Comorbidity Index; EBL = estimated blood loss; HRQOL = health-related quality of life; MCS = mental component summary; ODI = Oswestry Disability Index; PCS = physical component summary; SRS-22r = Scoliosis Research Society-22r Questionnaire. 
$\mathrm{T}$ He role of sex in adult spinal deformity (ASD) surgery outcomes has not been extensively investigated. In contrast, several studies in the pediatric deformity population have demonstrated that sex does play a role in perioperative outcomes. ${ }^{11,16,22}$ These studies found that male adolescent idiopathic scoliosis (AIS) patients had greater preoperative curve magnitude, less preoperative curve flexibility, and less deformity correction than female patients. Male patients also had greater estimated blood loss (EBL), longer operative duration, and higher complication rates..$^{1,22}$ Male AIS patients were also found to have better preoperative health-related quality of life (HRQOL) scores for self-image and mental health and better postoperative pain and mental health at 2 years after surgery. ${ }^{16}$

However, the influence of sex in adults with spinal deformity is not well understood. ASD includes a wide spectrum of pathologies, including untreated or progressive idiopathic scoliosis, degenerative scoliosis, kyphosis, and sagittal decompensation. Baseline patient health and functional status is also more variable than in the AIS population. For these reasons, identifying whether sex is a significant determining factor for ASD outcomes is difficult. Female patients undergoing lumbar surgery may have slightly more preoperative disability and back pain than male patients, although male patients more frequently stated that lumbar surgery met their expectations of symptom relief. ${ }^{4}$ Male patients with chronic spinal disability had higher physical function before and after treatment, and women in this population were more likely to have symptoms of depression. While these findings suggest a potential role of sex in adult spinal disorders, no studies have specifically addressed this question in the deformity population. ${ }^{13}$

The objective of this study was to determine whether sex influences operative morbidity, complications, radiographic correction, or HRQOL in ASD surgery. We hypothesized that male ASD patients would have more intraoperative blood loss and a longer operative time due to a more muscular body habitus and stiffer deformities, thereby leading to more complications and worse HRQOL scores. Surgeons must understand the association between sex and perioperative outcomes to allow the appropriate counseling of ASD patients in a shared decision-making model. Moreover, in a value-driven health care economy, we must make informed decisions regarding the use of antifibrinolytics, osteotomies, fusion augments, and spine implant density and how sex may affect these decisions.

\section{Methods \\ Multicenter Cohort Study}

A multicenter database of consecutively enrolled ASD patients was used to perform a retrospective cohort study. Patients provided informed consent for inclusion, and each of the 11 participating enrollment centers obtained institutional review board approval. Patients were enrolled from January 1, 2008, to July 31, 2014. All patients enrolled in this time frame were eligible for inclusion in the analyses of intraoperative and perioperative complications. Patients enrolled up to August 31, 2012, were considered eligible for 2-year follow-up and included in the 2-year analysis. Criteria for patient inclusion in the database were age older than 18 years and at least 1 of the following characteristics: idiopathic or degenerative scoliosis $\geq 20^{\circ}$, thoracic kyphosis $>60^{\circ}$, sagittal vertical axis $>5 \mathrm{~cm}$, or pelvic tilt $>$ $25^{\circ}$. Patients with inflammatory, posttraumatic, neuromuscular, infectious, or neoplastic etiologies were excluded, as were patients who underwent revision spine fusion.

We queried this database using additional criteria to create 2 cohorts: 1 male and 1 female cohort. Additional criteria were primary ASD surgery, instrumented arthrodesis of at least 5 levels, posterior-only approach, and minimum 2-year follow-up. Primary outcomes were estimated blood loss (EBL), operative duration, radiographic correction, need for revision surgery, peri- and postoperative complications, and HRQOL outcomes. The HRQOL instruments collected were the Scoliosis Research Society22r (SRS-22r) Questionnaire, Oswestry Disability Index (ODI), and SF-36; the SF-36 scores were reported as the physical component summary (PCS) and mental component summary (MCS). Complications that extended the length of stay and/or required any procedural intervention were classified as "major." Complications that were managed with observation and/or did not affect the length of stay were classified as "minor."

The independent t-test and chi-square test were used for comparisons of the continuous and categorical variables, respectively, between cohorts. If the expected count for a chi-square comparison was less than 5, the Fisher exact test was used. No correction for multiple comparisons was performed for the baseline data, as we preferred to commit a Type 1 error rather than a Type 2 error when searching for differences between groups. The rates of complications per patient were compared using the chisquare test. The number of complications was also compared by category (cancer, cardiopulmonary, electrolyte, gastrointestinal, implant related, infection, musculoskeletal, neurological, operative, radiographic, renal, vascular, wound, or other). A correction for multiple comparisons was performed for these comparisons, and significance was defined as $p<0.004$. Poisson multivariate regression was used to evaluate sex differences in the complications at the intraoperative, perioperative, and postoperative time points (6 weeks, 12 months, and 24 months) by controlling for baseline confounding variables. The analysis controlled for age, body mass index (BMI), Charlson Comorbidity Index (CCI), and number of levels fused.

The responder analysis was performed to compare the number of patients who achieved improvement at or above the minimum clinically important difference for ODI, SRS-Pain, SRS-Activity, SRS-Appearance, SRS-Mental, and SF-36 PCS at a minimum follow-up of 2 years.

\section{Results}

A total of 421 patients met the inclusion criteria. Of these patients, 409 (97\%; 90 male and 319 female patients) had complete baseline and perioperative data. Two hundred sixty-five patients met the inclusion criteria and were eligible for 2-year follow-up. Two hundred five patients (77\%) had complete 2-year follow-up data for analysis (34 
TABLE 1. Comparison of preoperative demographic, radiographic, and $H R Q O L$ data

\begin{tabular}{|c|c|c|c|}
\hline Baseline Parameter & Men & Women & $p$ Value \\
\hline No. of patients & 90 & 319 & \\
\hline \multicolumn{4}{|l|}{ Demographic } \\
\hline Age, yrs & $58.3(1.8)$ & $55.0(0.9)$ & 0.08 \\
\hline $\mathrm{BMI}, \mathrm{kg} / \mathrm{m}^{2}$ & $29.1(0.8)$ & $26.4(0.3)$ & 0.001 \\
\hline $\mathrm{CCl}$ & $2.0(0.2)$ & $1.3(0.1)$ & 0.007 \\
\hline \multicolumn{4}{|l|}{ Ethnicity, n (\%) } \\
\hline Caucasian & $80(91)$ & $272(90)$ & \multirow{5}{*}{0.98} \\
\hline African American & $4(5)$ & $12(4)$ & \\
\hline Hispanic & $2(2)$ & $8(3)$ & \\
\hline Asian & $1(1)$ & $6(2)$ & \\
\hline Other & $1(1)$ & $4(1)$ & \\
\hline \multicolumn{4}{|l|}{ Radiographic } \\
\hline \multicolumn{4}{|l|}{ Sagittal } \\
\hline C-7 SVA, mm & $64.3(7.5)$ & $60.1(4.5)$ & 0.66 \\
\hline Thoracic kyphosis, ${ }^{\circ}$ & $36.2(2.3)$ & $35.0(1.1)$ & 0.59 \\
\hline Pelvic tilt, ${ }^{\circ}$ & $22.5(1.1)$ & $23.1(0.7)$ & 0.62 \\
\hline Pelvic incidence, ${ }^{\circ}$ & $55.6(1.2)$ & $55.1(0.7)$ & 0.71 \\
\hline Lumbar lordosis, $^{\circ}$ & $37.4(2.4)$ & $37.0(1.3)$ & 0.89 \\
\hline $\begin{array}{l}\text { Pelvic incidence-lumbar } \\
\text { lordosis mismatch, }^{\circ}\end{array}$ & $15.6(2.3)$ & $14.6(1.3)$ & 0.71 \\
\hline \multicolumn{4}{|l|}{ Coronal, $^{\circ}$} \\
\hline Proximal thoracic & $23.0(3.5)$ & $26.0(1.1)$ & 0.29 \\
\hline Main thoracic & $24.9(7.4)$ & $28.8(2.6)$ & 0.57 \\
\hline Thoracolumbar & $15.9(7.1)$ & $10.6(3.8)$ & 0.54 \\
\hline Lumbar & $13.1(3.9)$ & $20.9(2.2)$ & 0.11 \\
\hline $\begin{array}{l}\text { SRS-Schwab coronal curve } \\
\text { type }\end{array}$ & & & $<0.001$ \\
\hline $\mathrm{N}^{*}$ & 49.4 & 24.6 & \\
\hline $\mathrm{T}$ & 6.7 & 7.1 & \\
\hline$L^{*}$ & 23.6 & 38.6 & \\
\hline$D$ & 20.2 & 29.6 & \\
\hline Pelvic tilt modifier & & & 0.69 \\
\hline$<20^{\circ}$ & 42 & 37.2 & \\
\hline $20-30^{\circ}$ & 35.2 & 36.9 & \\
\hline$>30^{\circ}$ & 22.7 & 25.9 & \\
\hline Global alignment modifier & & & 0.43 \\
\hline$S V A<4 \mathrm{~cm}$ & 39.5 & 45.6 & \\
\hline SVA $4-9.5 \mathrm{~cm}$ & 31.4 & 24.8 & \\
\hline$S V A>9.5 \mathrm{~cm}$ & 29.1 & 29.6 & \\
\hline $\begin{array}{l}\text { Pelvic incidence-lumbar } \\
\text { lordosis modifier }\end{array}$ & & & 0.89 \\
\hline$<10^{\circ}$ & 40.9 & 42.7 & \\
\hline $10-20^{\circ}$ & 22.7 & 20.4 & \\
\hline$>20^{\circ}$ & 36.4 & 36.9 & \\
\hline \multicolumn{4}{|l|}{ HRQOL outcomes } \\
\hline ODI & $43.2(1.8)$ & $42.4(1.1)$ & 0.72 \\
\hline \multicolumn{4}{|l|}{ SRS-22r } \\
\hline Activity & $2.8(0.1)$ & $2.9(0.1)$ & 0.42 \\
\hline Pain & $2.4(0.1)$ & $2.5(0.1)$ & 0.24 \\
\hline
\end{tabular}

» CONTINUED FROM PREVIOUS COLUMN

TABLE 1. Comparison of preoperative demographic, radiographic, and $H R Q O L$ data

\begin{tabular}{cclc}
\hline Baseline Parameter & Men & Women & p Value \\
\hline HRQOL outcomes (continued) & & & \\
\hline SRS-22r (continued) & & & \\
\hline Appearance & $2.5(0.1)$ & $2.4(0.04)$ & 0.20 \\
\hline Mental & $3.4(0.1)$ & $3.4(0.1)$ & 0.61 \\
\hline Satisfaction & $2.6(0.1)$ & $2.7(0.1)$ & 0.43 \\
\hline Total & $2.8(0.1)$ & $2.8(0.03)$ & 0.56 \\
\hline SF-36 & & & \\
\hline PCS & $31.0(1.1)$ & $32.7(0.6)$ & 0.21 \\
\hline MCS & $44.3(1.7)$ & $45.3(0.8)$ & 0.59 \\
\hline
\end{tabular}

SVA = sagittal vertical axis.

Values are given as the mean (SEM) or percentage of patients unless indicated otherwise. Boldface type indicates statistical significance $(p<0.004)$.

* Statistically significant.

male and 171 female patients). Comparative baseline data are summarized in Table 1. Male patients had a higher mean \pm SEM preoperative BMI $(29.1 \pm 0.8$ vs $26.4 \pm 0.3$ $\left.\mathrm{kg} / \mathrm{m}^{2} ; \mathrm{p}=0.001\right)$ and CCI score $(2.0 \pm 0.2$ vs $1.3 \pm 0.1 ; \mathrm{p}$ $=0.007)$. However, there were no preoperative differences in any of the HRQOL scores or radiographic measurements. There were more pure sagittal plane deformities in the male cohort (49.4\% of male patients had SRS-Schwab coronal curve Type N vs $24.6 \%$ of female patients; $\mathrm{p}<$ 0.05 ) and more lumbar coronal plane deformities in the female cohort ( $23.6 \%$ of male patients had Type L vs $38.6 \%$ of female patients; $\mathrm{p}<0.05$ ).

Male patients had significantly greater mean \pm SEM EBL $(2373 \pm 202 \mathrm{ml}$ vs $1829 \pm 81 \mathrm{ml} ; \mathrm{p}=0.01)$ (Table 2$)$. However, transfusion volumes during the hospital stay did not differ significantly. Women underwent fusion of an additional mean 1.4 levels compared with men $(\mathrm{p}=0.001)$.

TABLE 2. Comparison of operative data

\begin{tabular}{lccc}
\hline \multicolumn{1}{c}{ Operative Parameter } & Men & Women & p Value \\
\hline No. of patients & 90 & 319 & \\
\hline EBL, $\mathrm{ml}$ & $2373(201)$ & $1829(81)$ & 0.01 \\
\hline Op time, min & $400(13.7)$ & $391(6.9)$ & 0.57 \\
\hline No. of posterior levels fused & $10.7(0.3)$ & $12.1(0.2)$ & 0.001 \\
\hline $\begin{array}{l}\text { No. of posterior column } \\
\quad \text { osteotomies }\end{array}$ & $3.6(0.4)$ & $4.2(0.2)$ & 0.15 \\
\hline Autologous transfusion, $\mathrm{ml}$ & $583(214)$ & $441(127)$ & 0.57 \\
\hline Allogeneic transfusion, $\mathrm{ml}$ & $1485(209)$ & $1387(95)$ & 0.64 \\
\hline Surgical ICU LOS, hr & $52.0(8.9)$ & $48.1(3.4)$ & 0.68 \\
\hline Hospital LOS, days & $7.3(0.3)$ & $7.9(0.3)$ & 0.35 \\
\hline 3-column osteotomies, $\mathrm{n} \mathrm{( \% )}$ & $27(30)$ & $72(23)$ & 0.16 \\
\hline Fused to sacrum/pelvis, $\mathrm{n}(\%)$ & $68(76)$ & $235(74)$ & 0.79 \\
\hline
\end{tabular}

LOS = length of stay.

Values are given as the mean (SEM) unless indicated otherwise. Boldface type indicates statistical significance $(p<0.004)$. 
TABLE 3. Complication rates by type and sex

\begin{tabular}{lccc}
\hline Complications & Men & Women & p Value \\
\hline No. of patients & 90 & 319 & \\
\hline Intraop complications & & & \\
\hline Minor & $17(19)$ & $43(13)$ & 0.19 \\
\hline Major & $13(14)$ & $35(11)$ & 0.38 \\
\hline Total & $26(29)$ & $70(22)$ & 0.14 \\
\hline Periop complications & & & \\
\hline Minor & $14(16)$ & $75(24)$ & 0.10 \\
\hline Major & $15(17)$ & $52(16)$ & 0.95 \\
\hline Total & $26(29)$ & $110(34)$ & 0.28 \\
\hline Postop complications & & & \\
\hline Minor & $13(14)$ & $39(12)$ & 0.64 \\
\hline Major & $17(19)$ & $53(17)$ & 0.50 \\
\hline Total & $27(30)$ & $86(27)$ & 0.50 \\
\hline Return to surgery & & \\
\hline Immediate reop & $3(3)$ & $3(1)$ & $0.12^{*}$ \\
\hline Periop reop & $7(8)$ & $16(5)$ & $0.31 \dagger$ \\
\hline Late reop & $12(13)$ & $29(9)$ & $0.24 \dagger$ \\
\hline
\end{tabular}

Values are given as the number of patients (\%).

* Determined using the Fisher exact test.

$\dagger$ Determined using the chi-square test.

The mean number of posterior column osteotomies, number of 3-column osteotomies, and rates of fusion to the sacrum did not differ significantly between sexes. Similarly, mean operative time, mean number of hours in postsurgical intensive care, and mean hospital stay did not differ between men and women.

Multivariate regression analysis of the complication rates did not demonstrate significant associations with sex at any of the 3 time points after controlling for age, BMI, $\mathrm{CCI}$, and levels fused. After subdividing the analysis of complications in each time frame by major, minor, and total complications, again no significant differences were found between sex (Table 3). No sex differences in the reoperation rates were identified (Table 3). No differences were found in any complication category between sexes.

At the minimum 2-year follow-up, final radiographic measurements did not differ significantly between sexes (Table 4). Similarly, changes in the mean HRQOL scores from baseline to the minimum 2-year follow-up were not significantly different (Table 4). There were no differences in the number of patients who achieved HRQOL improvements at or above the minimum clinically important differences for ODI, SRS-Pain, SRS-Activity, SRS-Appearance, SRS-Mental, and SF-PCS.

\section{Discussion}

Male sex has been associated with worse outcomes in pediatric spinal deformity surgeries. ${ }^{5,11,16} \mathrm{We}$ sought to investigate the association between male sex and poor outcomes in a granular, multicenter database of ASD surgeries. We found no association between sex and perioperative complications and no evidence supporting worse
TABLE 4. Changes in radiographic measures and HRQOL outcomes at the 2-year follow-up

\begin{tabular}{|c|c|c|c|}
\hline Outcome & $\begin{array}{l}\text { Change in } \\
\text { Male Cohort }\end{array}$ & $\begin{array}{c}\text { Change in } \\
\text { Female Cohort }\end{array}$ & $\begin{array}{c}\mathrm{p} \\
\text { Value }\end{array}$ \\
\hline \multicolumn{4}{|l|}{ Radiographic } \\
\hline C-7 SVA, mm & $-31.5(12.4)$ & $-26.4(4.8)$ & 0.68 \\
\hline Thoracic kyphosis, $^{\circ}$ & $-8.7(2.3)$ & $-7.9(1.4)$ & 0.80 \\
\hline Pelvic tilt, ${ }^{\circ}$ & $-2.6(1.1)$ & $-1.7(0.6)$ & 0.56 \\
\hline Lumbar lordosis, $^{\circ}$ & $12.3(3.1)$ & $12.6(1.3)$ & 0.86 \\
\hline $\begin{array}{l}\text { Final pelvic incidence-lum- } \\
\text { bar lordosis mismatch, }{ }^{\circ}\end{array}$ & $-11.2(3.3)$ & $-9.7(1.3)$ & 0.66 \\
\hline Coronal proximal thoracic, ${ }^{\circ}$ & $3.5(6.0)$ & $12.0(1.6)$ & 0.06 \\
\hline Coronal main thoracic, ${ }^{\circ}$ & $6.9(14.4)$ & $12.6(2.7)$ & 0.53 \\
\hline Coronal thoracolumbar, ${ }^{\circ}$ & $9.1(6.3)$ & $8.7(3.0)$ & 0.97 \\
\hline Coronal lumbar, $^{\circ}$ & $8.0(4.7)$ & $10.3(2.3)$ & 0.68 \\
\hline \multicolumn{4}{|l|}{ HRQOL outcomes } \\
\hline ODI & $-14.1(2.4)$ & $-14.1(1.5)$ & 0.99 \\
\hline \multicolumn{4}{|l|}{ SF-36 } \\
\hline PCS & $8.3(1.7)$ & $7.1(0.9)$ & 0.57 \\
\hline MCS & $8.0(2.4)$ & $4.4(1.1)$ & 0.19 \\
\hline \multicolumn{4}{|l|}{ SRS-22r } \\
\hline Activity & $0.5(0.1)$ & $0.6(0.1)$ & 0.92 \\
\hline Pain & $1.0(0.1)$ & $0.9(0.1)$ & 0.69 \\
\hline Appearance & $1.0(0.2)$ & $1.3(0.1)$ & 0.21 \\
\hline Mental & $0.5(0.1)$ & $0.4(0.1)$ & 0.51 \\
\hline Satisfaction & $1.4(0.3)$ & $1.5(0.1)$ & 0.88 \\
\hline Total & $0.8(0.1)$ & $0.8(0.1)$ & 0.80 \\
\hline \multicolumn{4}{|l|}{$\begin{array}{l}\text { Responder analysis, } \% \text { of } \\
\text { patients who achieved } \\
\text { minimum clinically important } \\
\text { difference at } 2 \text { yrs }\end{array}$} \\
\hline ODI & 36 & 47 & 0.30 \\
\hline \multicolumn{4}{|l|}{ SRS-22r } \\
\hline Activity & 58 & 64 & 0.11 \\
\hline Pain & 70 & 63 & 0.24 \\
\hline Appearance & 59 & 77 & 0.12 \\
\hline Mental & 50 & 45 & 0.86 \\
\hline SF-36 PCS & 59 & 54 & 0.50 \\
\hline
\end{tabular}

Values are given as the mean (SEM) unless indicated otherwise.

HRQOL outcomes for men. We did find greater EBL in male patients, although this did not seem to affect the clinical course and did not cause greater exposure to allogeneic blood transfusions.

There is a paucity of literature on the role of sex in the management of ASD. The prevalence of ASD has been reported to be as high as $10 \%-30 \%$ in the general population, and its incidence as well as the use of surgical treatment are increasing as the population ages. ${ }^{1,6,8,12,17}$ Women are seemingly more frequently affected with ASD than men, although in a study of elderly volunteers there was no difference in the prevalence of adult scoliosis between sexes. ${ }^{19-21}$ High-quality longitudinal studies comparing 
ASD progression in men and women are lacking, but previous reports have not found differences in deformity progression between sexes. ${ }^{9}$

The pediatric spine literature suggests that sex may play an important role in the surgical outcomes of AIS patients. ${ }^{5,11,16,22}$ Male AIS patients may have greater mean intraoperative blood loss (1342 ml vs $898 \mathrm{ml} ; \mathrm{p}=0.001)$ and more pain on the 1st postoperative day. ${ }^{11}$ This cohort also reported a higher complication rate in men than women $(16 \%$ vs $12 \% ; p=0.04)$. Sucato et al. similarly found greater mean blood loss (1148 $\mathrm{ml}$ vs $944 \mathrm{ml} ; \mathrm{p}<0.05)$ and longer mean operative time (263 minutes vs 202 minutes; $\mathrm{p}<0.05)$ in male patients, but did not find any difference in the complication rates. ${ }^{22}$ These authors found that male patients experienced less coronal curve correction than female patients ( $43 \%$ vs $42 \%$; $p<0.05$ ), and this finding was not replicated by Marks et al. or Helenius et al.,5,11,22

AIS has, however, a more consistent patient population and pathology than ASD, and lends itself to analysis. Determining the role of sex in the surgical outcomes of ASD patients has proven difficult due to the heterogeneity of this diagnosis and the relative paucity of men in studies of these pathologies..$^{15}$ Many cases of ASD are driven by degeneration and progressive sagittal malalignment rather than an underlying idiopathic problem. Numerous patients have had prior spine procedures, including long-segment fusions, although in an effort to homogenize our study population these patients were excluded.

Our findings differ from several published studies on the complication rates in adult spine fusion patients. Basques et al. reported that female patients undergoing lumbar fusion have higher perioperative transfusion requirements. ${ }^{2}$ Comparing transfusion rates is difficult in the absence of clearly defined transfusion criteria. Nevertheless, we did not observe any relationship between sex and perioperative transfusions. Rao et al. found that male patients were at a higher risk for postoperative infections following spinal fusions, though this population included patients with trauma and malignancy, which carry different risks for infection than ASD patients. ${ }^{14}$ Triebel et al. observed that women undergoing lumbar fusion for degenerative disk disease had worse preoperative pain, disability, and quality of life than men, but we did not observe these outcomes in our ASD patients. However, in a similar finding to our study, the authors found that men and women had equivalent quality of life and returned to work 2 years after surgery. ${ }^{23}$

A meta-analysis and systematic review explored the relationship between sex and postoperative mortality and other complications after spine surgery. ${ }^{18}$ The diseases studied were not limited to spinal deformity. In this analysis of 50 studies, male patients were at greater risk for mortality with an OR of 1.63 ( $\mathrm{p}<0.001)$. Of note, this is a relatively small increase in overall risk as mortality is uncommon and may not be of great clinical significance. Sex did not increase the risk for other complications, whether analyzed in total (OR 1.04, $\mathrm{p}=0.42)$ or specifically for surgical site infection (OR 0.92, $\mathrm{p}=0.72)$. Their findings for morbidity mirror our results in the ASD population, with no risk attributed to male sex. A large administrative database study reported a 30-day complication prevalence of $28.4 \%$, similar to the $22 \%-34 \%$ total complication rate we have found here. ${ }^{10}$

In contrast to our findings, Kothari et al. concluded that female sex was associated with a greater risk for 30-day complications, intraoperative and postoperative transfusion, and longer hospital length of stay in a multivariate analysis. ${ }^{10}$ This study included a large number of patients, and the ACS NSQIP (American College of Surgeons National Surgical Quality Improvement Program) database requires participating hospitals to have on-site clinical reviewers to maintain accurate data. However, in these types of administrative database queries, the inclusion criteria are not discrete, as with our multicenter cohort; therefore, the etiology and radiographic severity of the included patients cannot be ascertained. Also, there was no way to separate primary from revision spine fusion patients. Importantly, surgical details known to influence complication rates such as the use of 3-column osteotomies and the surgical approach could not be extracted from the NSQIP data, and the analysis of complications was limited to a 30-day window. ${ }^{7}$ We believe the discrepancy in the conclusions between Kothari et al. and our study are likely due to these limitations of the source database.

The limitations of our study include its retrospective methodology and the inherent heterogeneity of the etiologies in the ASD population. Unlike the pediatric AIS studies, our ASD population included patients whose primary deformity may have been primarily in the coronal or sagittal planes, or even both. Thus, there may be differences within ASD subpopulations based on deformity type that could not be detected with our data and methodology. Furthermore, we investigated a specific cohort of ASD patients, i.e., those with primary deformities treated with an all-posterior approach. Our findings may not extrapolate to other types of ASD, particularly revision spinal deformity, and some sex-specific complications may result in different findings for reconstructions including anterior approaches (e.g., retrograde ejaculation). Those patients who were lost to follow-up may have had poorer outcomes than those who completed 2-year follow-up, thereby potentially introducing bias into our conclusions. ${ }^{3}$ Finally, there were more female than male patients in our study population. We think that the regression analysis adequately controls for this difference and accounts for the small baseline differences between the sex groups.

\section{Conclusions}

Sex was not associated with differences in complications, radiographic correction, or HRQOL after primary all-posterior ASD surgeries in a large observational cohort. Male patients did have greater mean EBL, and continued efforts to minimize blood loss through modern blood and fluid management strategies are needed. Given the frequency of complications in ASD surgery, further work is needed to identify the risk factors for complications, both to improve the results of surgery and manage patient expectations through a shared decision-making process. The effect of sex on patient-reported outcomes and complications in revision surgeries and in those patients undergoing additional anterior and lateral proce- 
dures must be investigated before definitive conclusions can be made.

\section{References}

1. Ailon T, Smith JS, Shaffrey CI, Lenke LG, Brodke D, Harrop JS, et al: Degenerative spinal deformity. Neurosurgery 77 (Suppl 4):S75-S91, 2015

2. Basques BA, Anandasivam NS, Webb ML, Samuel AM, Lukasiewicz AM, Bohl DD, et al: Risk factors for blood transfusion with primary posterior lumbar fusion. Spine (Phila Pa 1976) 40:1792-1797, 2015

3. Dettori JR: Loss to follow-up. Evid Based Spine Care J 2:7-10, 2011

4. Elsamadicy AA, Reddy GB, Nayar G, Sergesketter A, Zakare-Fagbamila R, Karikari IO, et al: Impact of gender disparities on short-term and long-term patient reported outcomes and satisfaction measures after elective lumbar spine surgery: a single institutional study of 384 patients. World Neurosurg 107:952-958, 2017

5. Helenius I, Remes V, Yrjönen T, Ylikoski M, Schlenzka D, Helenius M, et al: Does gender affect outcome of surgery in adolescent idiopathic scoliosis? Spine (Phila Pa 1976) 30:462-467, 2005

6. Jimbo S, Kobayashi T, Aono K, Atsuta Y, Matsuno T: Epidemiology of degenerative lumbar scoliosis: a communitybased cohort study. Spine (Phila Pa 1976) 37:1763-1770, 2012

7. Kelly MP, Lenke LG, Shaffrey CI, Ames CP, Carreon LY, Lafage V, et al: Evaluation of complications and neurological deficits with three-column spine reconstructions for complex spinal deformity: a retrospective Scoli-RISK-1 study. Neurosurg Focus 36(5):E17, 2014

8. Kobayashi T, Atsuta Y, Takemitsu M, Matsuno T, Takeda $\mathrm{N}$ : A prospective study of de novo scoliosis in a community based cohort. Spine (Phila Pa 1976) 31:178-182, 2006

9. Korovessis P, Piperos G, Sidiropoulos P, Dimas A: Adult idiopathic lumbar scoliosis. A formula for prediction of progression and review of the literature. Spine (Phila Pa 1976) 19:1926-1932, 1994

10. Kothari P, Lee NJ, Leven DM, Lakomkin N, Shin JI, Skovrlj B, et al: Impact of gender on 30-day complications after adult spinal deformity surgery. Spine (Phila Pa 1976) 41:11331138, 2016

11. Marks M, Petcharaporn M, Betz RR, Clements D, Lenke L, Newton PO: Outcomes of surgical treatment in male versus female adolescent idiopathic scoliosis patients. Spine (Phila Pa 1976) 32:544-549, 2007

12. McCarthy I, Hostin R, O'Brien M, Saigal R, Ames CP: Health economic analysis of adult deformity surgery. Neurosurg Clin N Am 24:293-304, 2013

13. McGeary DD, Mayer TG, Gatchel RJ, Anagnostis C, Proctor TJ: Gender-related differences in treatment outcomes for patients with musculoskeletal disorders. Spine J 3:197-203, 2003

14. Rao SB, Vasquez G, Harrop J, Maltenfort M, Stein N, Kaliyadan $\mathrm{G}$, et al: Risk factors for surgical site infections following spinal fusion procedures: a case-control study. Clin Infect Dis 53:686-692, 2011

15. Riley MS, Bridwell KH, Lenke LG, Dalton J, Kelly MP: Health-related quality of life outcomes in complex, adult spinal deformity surgery. J Neurosurg Spine [in press], 2017

16. Roberts DW, Savage JW, Schwartz DG, Carreon LY, Sucato DJ, Sanders JO, et al: Male-female differences in Scoliosis Research Society-30 scores in adolescent idiopathic scoliosis. Spine (Phila Pa 1976) 36:E53-E59, 2011

17. Robin GC, Span Y, Steinberg R, Makin M, Menczel J: Scoliosis in the elderly: a follow-up study. Spine (Phila Pa 1976) 7:355-359, 1982
18. Schoenfeld AJ, Reamer EN, Wynkoop EI, Choi H, Bono CM: Does patient sex affect the rate of mortality and complications after spine surgery? A systematic review. Clin Orthop Relat Res 473:2479-2486, 2015

19. Schwab F, Dubey A, Gamez L, El Fegoun AB, Hwang K, Pagala M, et al: Adult scoliosis: prevalence, SF-36, and nutritional parameters in an elderly volunteer population. Spine (Phila Pa 1976) 30:1082-1085, 2005

20. Schwab FJ, Blondel B, Bess S, Hostin R, Shaffrey CI, Smith JS, et al: Radiographical spinopelvic parameters and disability in the setting of adult spinal deformity: a prospective multicenter analysis. Spine (Phila Pa 1976) 38:E803-E812, 2013

21. Schwab FJ, Smith VA, Biserni M, Gamez L, Farcy JP, Pagala M: Adult scoliosis: a quantitative radiographic and clinical analysis. Spine (Phila Pa 1976) 27:387-392, 2002

22. Sucato DJ, Hedequist D, Karol LA: Operative correction of adolescent idiopathic scoliosis in male patients. A radiographic and functional outcome comparison with female patients. J Bone Joint Surg Am 86-A:2005-2014, 2004

23. Triebel J, Snellman G, Sandén B, Strömqvist F, Robinson Y: Women do not fare worse than men after lumbar fusion surgery: two-year follow-up results from 4,780 prospectively collected patients in the Swedish National Spine Register with lumbar degenerative disc disease and chronic low back pain. Spine J 17:656-662, 2017

\section{Disclosures}

A grant from DePuy Synthes Spine to the International Spine Study Group Foundation supported this work.

Dr. Ames: employee of the University of California, San Francisco; consultant for Stryker, Medtronic, and DePuy Synthes; patent holder with Fish \& Richardson, PC; and financial relationships with Stryker and Biomet Spine. Dr. Bess: consultant for K2 Medical and AlloSource; patent holder with Innovasis and K2 Medical; clinical or research support for the study described from DePuy Synthes, K2 Medical, and NuVasive; and non-studyrelated clinical or research support from Orthofix and Medtronic. Dr. Bumpass: consultant for Acuity Surgical and speaking fees from Medtronic. Dr. Burton: consultant for DePuy Synthes and AlloSource and patent holder with DePuy Synthes. Dr. Gum: consultant for Medtronic, DePuy, Alphatec, Stryker, K2M, and Acuity. Dr. Hostin: consultant for DePuy Synthes and non-studyrelated clinical or research support from NuVasive, Seeger, DJO, K2M, and DePuy Synthes. Dr. Klineberg: consultant for DePuy Synthes, Stryker, Springer, and Trevana; honoraria and fellowship grant support from AOSpine; and honoraria from K2M. Dr. Kelly: non-study-related clinical or research support from OREF, AOSpine, CSRS, and the Barnes Jewish Foundation. Dr. Lafage: stock ownership in Nemaris Inc.; non-study-related clinical or research support from DePuy Spine, K2M, Stryker, and NuVasive through ISSGF; consultant for NuVasive; and speaking and teaching arrangements with DePuy Spine, MSD, and AOSpine. Dr. Lenke: consultant for Medtronic, K2M (relationship ended in 2014), and DePuy Synthes (relationship ended in 2014) (all monies donated to a charitable foundation); royalties from Medtronic and Fox Rothschild, LLC; grant support from DePuy Synthes, the Scoliosis Research Society, EOS, Scoliosis Straight Foundation, and AOSpine; airfare and hotel reimbursement from the Scoliosis Research Society, EOS, AOSpine, Broadwater, Seattle Science Foundation, Stryker Spine, and The Spinal Research Foundation; fellowship support from AOSpine; expert witness in a patent infringement case for Quality Medical Publishing; and philanthropic research funding from the Evans family and Fox Family Foundation. Dr. Mundis: consultant for NuVasive, K2M, and 
AlloSource and patent holder with NuVasive and K2M. Dr. Neuman: non-study-related clinical or research support from DePuy Synthes. Dr. Schwab: consultant for Zimmer Biomet, MSD, K2M, Medicrea, and NuVasive; stock ownership in Nemaris Inc.; non-study-related clinical or research support from DePuy Spine, NuVasive, K2M, and Stryker; receives grants from ISSGF; and speaking and teaching arrangements with Zimmer Biomet, MSD, NuVasive, and K2. Dr. Shaffrey: stock ownership in NuVasive; consultant for NuVasive, Medtronic, K2M, and Stryker; patent holder with NuVasive, Medtronic, and Zimmer Biomet; and non-study-related clinical or research support from DePuy Synthes, NuVasive, Medtronic, and K2M. Dr. Smith: consultant for Zimmer Biomet, NuVasive, K2M, AlloSource, and Cerapedics; royalties from Zimmer Biomet; fellowship funding from NREF and AOSpine; clinical or research support for the study described from DePuy Synthes/ISSG; and non-study-related clinical or research support from NREF.

\section{Author Contributions}

Conception and design: Kelly, Bumpass, Lenke, Gum, Neuman, Klineberg. Acquisition of data: Kelly, Shaffrey, Smith, Ames, Bess, Neuman, Klineberg, Mundis, Schwab, Lafage, Burton, Kebaish, Hostin. Analysis and interpretation of data: Kelly, Bumpass, Gum. Drafting the article: Kelly, Bumpass. Critically revising the article: Kelly, Bumpass, Lenke, Shaffrey, Smith, Klineberg, Mundis, Kim. Reviewed submitted version of manuscript: all authors. Approved the final version of the manuscript on behalf of all authors: Kelly. Statistical analysis: Kelly. Administrative/technical/material support: Lafage, Lafage. Study supervision: Shaffrey, Bess, Schwab, Burton.

\section{Correspondence}

Michael P. Kelly, Department of Orthopaedic Surgery, Washington University in St. Louis, One Barnes-Jewish Hospital Plaza, St. Louis, MO 63110. email: kellymi@wudosis.wustl.edu. 